\title{
Influence of the Consideration of Future Consequences on Financial Behavior: The Case of Japanese
} Individual Investors

\author{
Toru Suehiro ${ }^{1}$, Koichi Takeda ${ }^{2}$, Takashi Kozu ${ }^{3}$, Toshihiko TAKEMURA ${ }^{4}$ \\ ${ }^{1}$ Graduate School of Economics, Hosei University, Tokyo, Japan \\ ${ }^{2}$ Faculty of Economics, Hosei University, Tokyo, Japan \\ ${ }^{3}$ Ricoh Institute of Sustainability and Business, Tokyo, Japan \\ ${ }^{4}$ Faculty of Economics, Josai University, Japan \\ toru.suehiro@gmail.com, toru.suehiro@mizuho-sc.com, ktakeda@hosei.ac.jp, takashi.kozu@nts.ricoh.co.jp, \\ tkmrtshk@josai.ac.jp
}

\begin{abstract}
We analyze the impact of the "consideration of future consequences" (CFC) on the amount of financial assets and the liabilities of individual investors by applying a Tobit model to data from a web-based survey. We find that impatient individuals with high CFC have fewer deposits and financial asset balances. We also examine the influence of the CFC-immediate (CFC-I) and CFC-future (CFC-F) sub-indicators often used in psychology as well as CFC on financial asset balances and liabilities. CFC-I show concern with immediate consequences and also an index related to ego depletion. We find that the higher the CFC-I, the lower the amount of deposits and financial asset balances. However, CFC-F is a sub-indicator designating lack of concern with future consequences; thus, the higher the CFC-F, the larger the debt.
\end{abstract}

Keywords: Ratio of risky asset holding, individual investors, Web-based survey, Behavioral finance, Japan, Consideration of future consequences.

\section{Introduction}

To investigate the relationship between the various attributes (including psychological tendencies) of Japanese individual investors and their investment behavior, we use the "Survey on Japanese Individual Investors' Financial Behavior" and analyze the data from this survey (Kozu et al., 2012, Takeda et al., 2013). Following recent studies on behavioral economics and behavioral finance, in conducting behavioral analysis of individual investors, we use data that can be clearly classified by characteristics such as age, gender, holding status of assets, individual feelings, and also psychological tendencies. In this study, we thus analyze the influence of the consideration of future consequences (CFC) on the financial assets owned by individual investors based on demographic parameters from the web-based survey. Furthermore, we divide CFCs into CFC-immediate (CFC-I), which means "concerned with immediate consequences," and CFC-future (CFC-F), which refers to "concerned with future consequences," and comparatively analyze them. A Tobit model is then applied to the results, whose parameters are related to time and money preferences.

\section{Literature Review}

An early empirical study by Nakagawa and Katagiri (1999) uses micro data (individual data) on Japanese household asset allocation to analyze the reason the holding ratio of risky assets is lower in Japanese households than in other countries. The study shows that Japanese investors do not consider the profitability of assets significantly important, indicating a stronger tendency to value safety and liquidity than US investors. More recently, research on behavioral economics has also been conducted using behavioral characteristics data. Kinari and Tsutsui (2009) measure the psychological tendencies of an individual being an optimist, including not only demographic parameters, such as age and sex, but also personal psychological ones such as the time discount rate of individuals. They show that psychological tendencies have influences on the holding of financial assets. Prior studies on the influence of time discount rate of individuals are roughly divided into two categories: (1) the impact on the balance of financial assets and (2) the influence on the holding ratio of risky assets. Regarding the impact of the time discount rate on the balance of financial assets, many studies show that the amount of financial assets reduces as the time discount rate increases, and "impatient" individuals tend to value "current consumption" over "future consumption." For instance, Takeuchi and Hoshino (2014) find that the time discount rate has a significantly negative influence on the holding of financial assets. They show that the higher the time discount rate is, the lower the financial assets 
are. The authors conclude that the holding amount of financial assets, including risky assets, is small because individuals who are present-oriented and rational consume more.

This is based on the fact that the ratio of the time discount rate changes the evaluation of current and future consumption under the setup of the utility function in traditional economics theory. In other words, individuals with high time discount rates emphasize current consumption, meaning that savings for future consumption tend to be small. Feng et al. (2017) assert that the discount rate significantly reduces the probability of having bank deposits, postal savings, stocks, investment trusts, government bonds, and corporate pensions. However, most studies conducted in Japan on the influence of the time discount rate on personal financial asset formation compare the receipt of money between two points of time. As one of few exceptions, identify current bias by asking the qualitative question of how often the respondents did their homework as children. They find that those who are strongly focused on the present are less likely to hold financial assets. Ammerman and MacDonald (2017) summarize past research on the holding ratio of risky to financial assets. They show that whether the period is short- or long-term and the scale of profit and loss affect the impact of time discount rate on individual asset allocation. For example, if long-term investors are optimistic about future profits and the lower the time discount rate, the more likely they are to hold many risky assets aiming for future profits.

However, if investors think that the risk of a financial crisis will increase in the near future, they would be pessimistic about future profit. In this case, investors believe that loss would occur and the lower the investors' time discount rate, the more likely to reduce their risk assets. The authors also summarize that the time discount rate factor affects an individual investor's asset allocation by combining the risky asset holding ratio with expected returns, among others. Webley and Nyhus (2013) analyze the characteristics of bias related to self-control (Self-Control) using 18- to 32-year-old Dutch voter data. They show an easy feature is to increase the proportion of cash out of the assets held (for quick consumption) to value short-term consumption, as bias is stronger. Ammerman and MacDonald (2017) also use Dutch population data to show that the cash holding ratio is high for individuals with a strong current bias that values, based on current bias parameters often used in psychology, among other fields. This current bias parameter is the CFC proposed by Strathman et al. (1994) and is often used for analyzing the behavioral characteristics of individuals. However, the only example is the study conducted by Ammerman and MacDonald (2017) using Dutch data, which uses a determinant of the asset holding amount of individual investors.

\section{Web-Based Survey and Framework}

Web-Based Survey: In this study, we used individual data collected using the Internet survey titled "Survey on Japanese Individual Investors' Financial Behavior 2017" (hereinafter, the "2017 Survey") conducted in March 2017'. The subjects were male and female (Japanese) aged 20 years and over having invested in stock or other types of mutual funds (e.g., stock mutual funds, balanced mutual funds). We conducted a preliminary survey of about 20,000 people by extracting 1,233 people to investigate whether the subjects of the survey satisfy the conditions. In addition, we used an oversampling technique and calculated the time spent by each respondent to answer about 50 questions. Before beginning the statistical analysis, we excluded those observations for which the respondents took a short time to answer. After screening, the number of observations was reduced to 1,218 . Of the surveyed subjects, $75.3 \%$ were men, of which $60 \%$ had less than 5 million yen as income and $60 \%$ had less than 5 million yen as deposits and other financial assets. However, around $25 \%$ of respondents owned 10 million yen or more. Regarding the amount of liabilities, about $70 \%$ of respondents replied that they had zero liabilities. Regarding residential areas, the Kanto region is the largest in our sample (at around 40\%).

\footnotetext{
${ }^{1}$ Web-based (Internet) methods inevitably have data collection weaknesses, but it is not always desirable to use Internet surveys if the purpose of the survey is to provide useful information useful to individuals and organizations It has been suggested that decision making (The Japan Institute for Labor Policy and Training, 2005). These collected data are assumed to be useful for rational analysis. Specifically, observations with a response time of 6 minutes or less were excluded. This is less than half the average response time (about 12 minutes).
} 
Consideration of Future Consequences (CFC): Strathman et al. (1994) focus on future thought in relation to future prospects, conducting a study on CFC and creating a questionnaire including the 12 questions in Table 1. From the responses to the questionnaire, we can measure whether individuals tend to be affected by considering how their current behavior affects future results. Specifically, in many cases, factor analysis is applied to the answers to the 12 questions, and the score of the first factor is taken as a future result deliberation indicator showing the degree of consideration for each future result. Inoue and Arimitsu (2008) evaluate its usefulness by surveying Japanese CFCs by using the translated version of Strathman et al.'s (1994) questions into Japanese. In addition, Joireman et al. (2008) analyze the characteristics of CFC as CFC-I and CFC-F. While both indicators refer to CFC, we can divide the CFC results in relation to the present or future. Specifically, among the 12 questions in Table 1, the factor score as a result of factor analysis using only questions 1, 2, 6, 7, and 8 corresponds to CFC-F, and questions 3, 4, 5, 9, 10, 11, and 12 refer to CFC-I. Regarding these qualitative interpretations, according to Joireman et al. (2008), although both CFC-I and CFC$\mathrm{F}$ are related to the time discount rate, CFC-I also strongly related to ego depletion. In this study, we investigate CFC, CFC-I, and CFC-F using the Japanese translated version of the questions in Table 1. The answers are based on a five-point Likert scale: applicable, slightly applicable, indifferent, slightly inapplicable, and inapplicable.

\section{Table 1: Questions used to Investigate CFC Indicators}

\begin{tabular}{|c|l|}
\hline 1 & $\begin{array}{l}\text { I consider how things might be in the future and try to influence those things with my } \\
\text { day-to-day behavior }\end{array}$ \\
\hline 2 & $\begin{array}{l}\text { I often engage in a particular behaviors in order to achieve } \\
\text { outcomes that may not have resulted for many years. }\end{array}$ \\
\hline 3 & $\begin{array}{l}\text { I only act to satisfy immediate concerns, figuring the future } \\
\text { will take care of itself. }\end{array}$ \\
\hline 4 & $\begin{array}{l}\text { My behavior is only influenced by the immediate (i.e., a matter } \\
\text { of days or weeks) outcomes of my actions. }\end{array}$ \\
\hline 5 & $\begin{array}{l}\text { My convenience is a big factor in the decisions I make or the } \\
\text { actions I take. }\end{array}$ \\
\hline 6 & $\begin{array}{l}\text { I am willing to sacrifice my immediate happiness or wellbeing } \\
\text { in order to achieve future outcomes. }\end{array}$ \\
\hline 7 & $\begin{array}{l}\text { I think it is important to take warnings about negative outcomes seriously even if the } \\
\text { negative outcome will not occur for many years. }\end{array}$ \\
\hline 8 & $\begin{array}{l}\text { I think it is more important to perform a behavior with important distant consequences } \\
\text { than a behavior with less important immediate consequences. }\end{array}$ \\
\hline 9 & $\begin{array}{l}\text { I generally ignore warnings about possible future problems because I think the problems } \\
\text { will be resolved before they reach crisis level. }\end{array}$ \\
\hline 10 & $\begin{array}{l}\text { I think that sacrificing now is usually unnecessary since } \\
\text { future outcomes can be dealt with at a later time. }\end{array}$ \\
\hline 11 & $\begin{array}{l}\text { I only act to satisfy immediate concerns, figuring that I will take care of future problems } \\
\text { that may occur at a later date. }\end{array}$ \\
\hline 12 & $\begin{array}{l}\text { Since my day-to-day work has specific outcomes, it is more important to me than } \\
\text { behavior that has distant outcomes. }\end{array}$ \\
\hline
\end{tabular}

Model: Because the purpose of this research is to show the influence of the bias of CFC on individual investors' asset holding, the dependent variables are "deposit amount," "stock or other types of mutual funds" (e.g., stock mutual funds, balanced mutual funds), and "liability amount" the results on "deposit ratio" and "share or other types of mutual funds ratio" for total financial assets are summarized in the Appendix. The 2017 survey includes many questions that measure not only demographic attributes and the asset holding status of individual investors, but also individual behavioral characteristics commonly used in behavioral economics. We choose independent variables likely to affect the holding status of individual financial assets, 
as shown in Table 2. A linear regression that ignores this data function is highly biased towards underestimating the response to the amount of individual investor assets held in relation to covariates such as age. In other words, it is important to consider whether ego depletion influences deposit amounts with respect to current time valuation.

This result shows that the concept of the time discount rate in the traditional economic utility function depend on people's view of whether they should emphasize the present. High education dummy, investment experience dummy, risk aversion, or behavioral finance factors. Since the dependent variables are based on pre-specified answers, we use a Tobit model. The Tobit analysis is designed to estimate the linear relationships between the explanatory variables and the explained variable based on censoring from below and above, respectively. Censoring from above takes place when values at or above a threshold are converted to the threshold, so that the true value might be equal to the threshold, but it might also be higher. In the case of censoring from below, values at or below the threshold are censored (Green, 2012). Specifically, we used demographic parameters and CFC as independent variables (Model 1) for each dependent variable (three types), demographic parameters, CFC-F, and CFC-I (Model 2), respectively. The Kinki and Chubu regions account for the next largest groups. These three regions collectively account for nearly $80 \%$ of respondents.

Table 2: Dependent Variables

\begin{tabular}{|c|c|c|c|c|}
\hline Variables & Definition of variables & $\#$ & Mean & S.D. \\
\hline Amount of deposit & $\begin{array}{l}0 \text { JPY, } 0.01-0.5 \text { million JPY, } 0.5-1 \text { million JPY, 1-2 million } \\
\text { JPY, 2-3 million JPY, 3-5 million JPY, 5-7 million JPY, 7- } \\
10 \text { million JPY, 10-15 million JPY, 15-30 million JPY, } \\
3000 \text { million JPY or over } \\
\Rightarrow \\
0 \text { JPY, } 0.25 \text { million JPY, } 0.75 \text { million JPY, } 1.5 \text { million JPY, } \\
2.5 \text { million JPY, } 4 \text { million JPY, } 6 \text { million JPY, } 8.5 \text { million } \\
\text { JPY, } 12.5 \text { million JPY, } 22.5 \text { million JPY, } 30 \text { million JPY }\end{array}$ & 1218 & 811.9 & 908.8 \\
\hline $\begin{array}{l}\text { Amount of stock or } \\
\text { other types of mutual } \\
\text { funds (e.g., stock } \\
\text { mutual funds, balanced } \\
\text { mutual funds) }\end{array}$ & $\begin{array}{l}0 \text { JPY, } 0.01-0.5 \text { million JPY, } 0.5-1 \text { million JPY, 1-2 million } \\
\text { JPY, 2-3 million JPY, 3-5 million JPY, 5-7 million JPY, 7- } \\
10 \text { million JPY, 10-15 million JPY, 15-30 million JPY, } \\
3000 \text { million JPY or over } \\
\Rightarrow \\
0 \text { JPY, } 0.25 \text { million JPY, } 0.75 \text { million JPY, } 1.5 \text { million JPY, } \\
2.5 \text { million JPY, } 4 \text { million JPY, } 6 \text { million JPY, } 8.5 \text { million } \\
\text { JPY, } 12.5 \text { million JPY, } 22.5 \text { million JPY, } 30 \text { million JPY }\end{array}$ & 1218 & 647.3 & 829.6 \\
\hline $\begin{array}{l}\text { Stock of other financial } \\
\text { assets }\end{array}$ & $\begin{array}{l}0 \text { JPY, } 0.01-0.5 \text { million JPY, 0.5-1 million JPY, 1-2 million } \\
\text { JPY, 2-3 million JPY, 3-5 million JPY, 5-7 million JPY, 7- } \\
10 \text { million JPY, 10-15 million JPY, 15-30 million JPY, } \\
3000 \text { million JPY or over } \\
\Rightarrow \\
0 \text { JPY, } 0.25 \text { million JPY, } 0.75 \text { million JPY, } 1.5 \text { million JPY, } \\
2.5 \text { million JPY, } 4 \text { million JPY, } 6 \text { million JPY, } 8.5 \text { million } \\
\text { JPY, } 12.5 \text { million JPY, } 22.5 \text { million JPY, } 30 \text { million JPY }\end{array}$ & 1218 & 371.4 & 706.6 \\
\hline Amount of debt & $\begin{array}{l}0 \text { JPY, } 0.01-0.5 \text { million JPY, } 0.5-1 \text { million JPY, 1-2 million } \\
\text { JPY, 2-3 million JPY, 3-5 million JPY, 5-7 million JPY, 7- } \\
10 \text { million JPY, 10-15 million JPY, 15-30 million JPY, } \\
3000 \text { million JPY or over } \\
\Rightarrow \\
0 \text { JPY, } 0.25 \text { million JPY, } 0.75 \text { million JPY, } 1.5 \text { million JPY, } \\
2.5 \text { million JPY, } 4 \text { million JPY, } 6 \text { million JPY, } 8.5 \text { million } \\
\text { JPY, } 12.5 \text { million JPY, } 22.5 \text { million JPY, } 30 \text { million JPY }\end{array}$ & 1218 & 265.8 & 696.9 \\
\hline
\end{tabular}


Table 3: Independent Variables

\begin{tabular}{|c|c|c|c|c|}
\hline Variables & Definition of variables & $\#$ & Mean & S.D. \\
\hline Age & 1. $20 \mathrm{~s}, 2.30 \mathrm{~s}, 3.40 \mathrm{~s}, 4.50 \mathrm{~s}, 5.60 \mathrm{~s}$ or over & 1218 & 3.37 & 1.16 \\
\hline High education dummy & 1. College graduates or over, 0.0 ther & 1213 & 0.67 & 0.47 \\
\hline $\begin{array}{l}\text { Investment experience } \\
\text { dummy }\end{array}$ & 1. Having investment experiences over 10 years, 0. Other & 1218 & 0.52 & 0.50 \\
\hline Risk aversion & $\begin{array}{l}\text { When do you usually go out? At what probability of rain will } \\
\text { you take an umbrella when going out?" (0-100\%) }\end{array}$ & 1218 & 56.64 & 19.41 \\
\hline CFC & Factor score of CFC questions & 1218 & 0.00 & 0.91 \\
\hline CFC-F & Factor score of CFC-F questions & 1218 & 0.00 & 0.82 \\
\hline CFC-I & Factor score of CFC-I questions & 1218 & 0.00 & 0.90 \\
\hline
\end{tabular}

\section{Results}

Here, we discuss the results of the Tobit model described above. First, there is no difference in the amount of deposits, stocks, etc. based on gender. However, men have more liabilities than women. Regarding age, the results show that the higher the age, the more deposits and stocks an individual is likely to have and the lower the liability amount. In addition, people with education higher than the university level tend to have more deposits and stock holdings, while their amount of debt tends to be lower. People with long investment experience have large amounts of deposits and stock holdings. However, CFC, CFC-F, and CFC-I differ depending on the explained variables. With the deposit amount as a dependent variable, we find that the higher the CFC is (impatience), the lower the deposit amount. Although CFC-F is not statistically significant, CFC-I is significant. In other words, present-oriented individuals have fewer deposits. CFC, CFC-F, and CFC-I do not have a statistically significant impact on stocks as dependent variables. CFC does not have a statistically significant impact on debt amount as dependent variable. However, the effect of CFC-F is significant, and the individuals who do not value the future have higher amounts of debt.

Table 4: Estimation Results

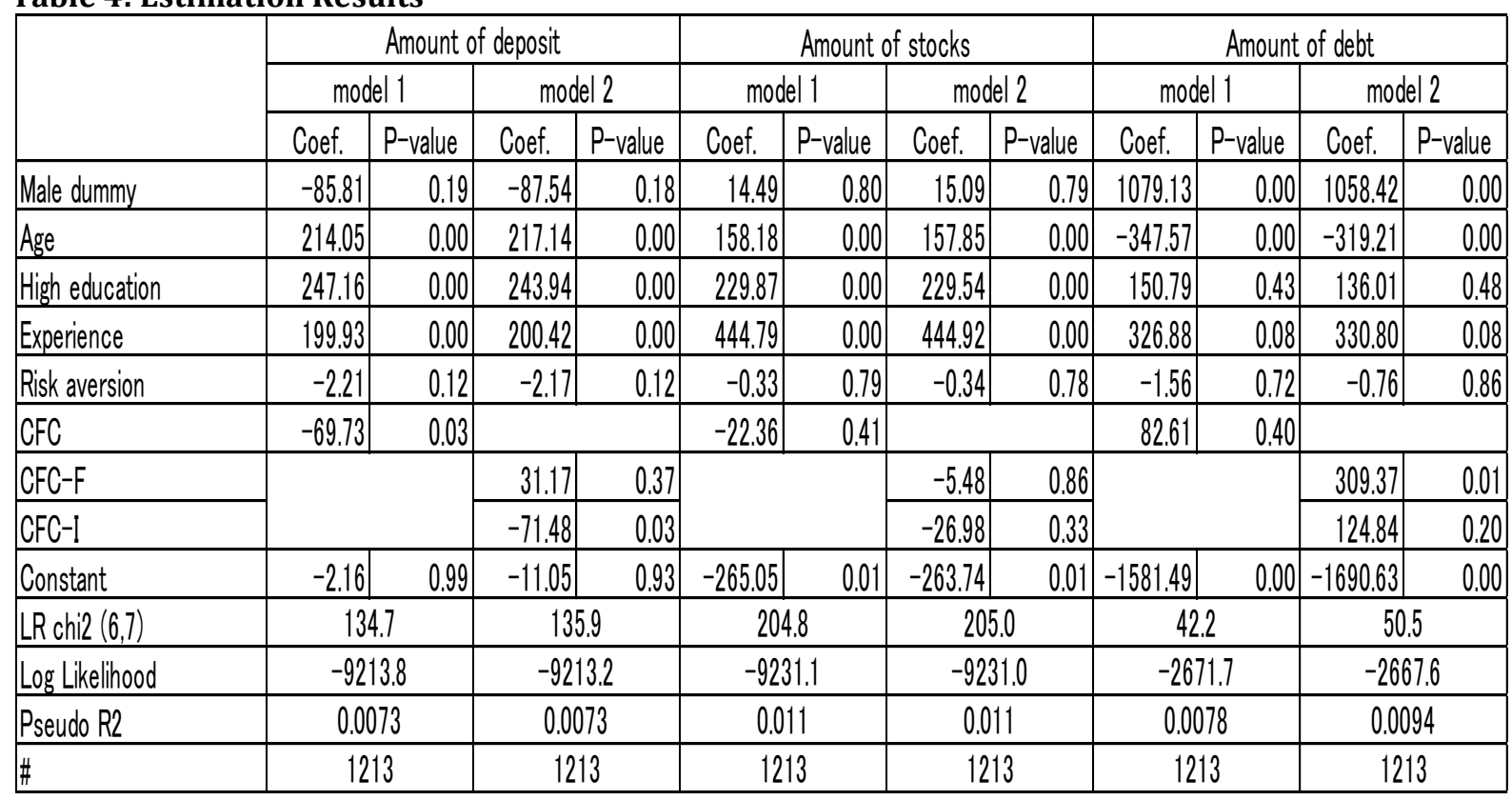




\section{Conclusion}

This is the first study to analyze the influence of CFC, CFC-I, and CFC-F on the balance of financial assets and liabilities by using data on Japanese individual investors. Regarding demographic parameters, our findings show that the higher the age is, the higher is the amounts of deposits, stocks, and mutual funds are. We can interpret the relationship as a higher age being associated with more financial assets due to the increased number of chances to increase savings. However, regarding the debt amount, the higher the age, the smaller the debt amount this is consistent with the life cycle viewpoint of taking mortgages and other loans at a young age. In addition, we find that individuals with long investment experiences tend to have more deposits and stocks, among others. However, CFC, CFC-F, and CFC-I have various influences on the individual holding of financial assets. Regarding CFC, the deposit amounts decrease as the indicator is high (short-term preference is strong and impatient). As discussed by Ammerman and MacDonald (2017), when CFC is low, impatient individuals value current consumption and the savings rate tends to be low.

Thus, their deposits tend to decrease. This result is consistent with result using Japanese data, although their CFC measurement method is different. Moreover, we find that CFC-I has a negative impact on the amount of deposits (i.e., the stronger the tendency to value the present, the fewer the deposits and overall financial assets are). In other words, the influence of ego depletion on the deposit amount is important with respect to current time valuation. As for the debt amount, we find that the higher the CFC-F is, the higher debt is. People with a high CFC-F do not place importance on the future, meaning that a low concern for future repayment leads to an increase in current debt. In this study, we analyzed the influence of CFC on the possession of financial assets, which has not been previously studied. As a result, we found that CFC-I has a negative impact on the amount of deposits (i.e., the stronger the tendency to value the present, the fewer the deposits and overall financial assets are). This study contributes to deepening our understanding of the determinants of the time discount rate.

Acknowledgements: This work is supported by the Japan Society for the Promotion of Science: Grant-in-Aid for Scientific Research (C) (17K03827).

\section{References}

Ammerman, D. A. \& MacDonald, M. (2017). Self-Control and Household Financial Asset Liquidity, Proceedings of the Association for Financial Counselling Planning and Education, 2016 Annual Research and Training Symposium, 93-102.

Feng, W., Paniny, C. \& Kinari, Y. (2017). The influence of behavioral economics factors in financial asset selection. Yucho Foundation Quarterly Personal Finance, 2017 spring (In Japanese).

Inoue, M. \& Arimitsu, K. (2008). Creation of a Japanese version of future results scrutiny scale and consideration of reliability / relevance. The Japanese Journal of Personality, 16(2), 256-258.

Joireman, J., Balliet, D., Sprott, D., Spangenberg, E. \& Schultz, J. (2008). Consideration of future consequences, ego-depletion, and self-control: Support for distinguishing between CFC-immediate and CFC-future sub-scales, Personality and Individual Differences, 48, 15-21.

Kinari, Y. \& Tsutsui, Y. (2009). Determinants of share of risky assets in Japan. Review of Monetary and Financial Studies, 29, 46-65.

Kitamura, T. \& Nakashima, K. (2010). Household portfolio selection of businessmen aged 30 to 49 years old. Journal of Behavioral Economics and Finance, 3, 50-69.

Kozu, T., Takemura, T. \& Takeda, K. (2012). An attribute analysis of Internet survey on individual investors' stock investment decisions. RISS Discussion Paper Series, 17, 1-16.

Nakagawa, S. \& Katagiri, T. (1999). Portfolio selection of financial assets by Japan's households: Why are Japan's households reluctant to invest in risky assets? (In Japanese).

Nogata, D. \& Takemura, T. (2017). Analysis on Japanese individual investors' ratio of risk asset holding: The role of information source. Individual Financing, Summer 2017, 17-24 (in Japanese).

Strathman, A., Gleicher, F., Boninger, D. S. \& Edwards, C. S. (1994). The consideration of future consequences: Weighing immediate and distant outcomes of behavior, Journal of Personality and Social Phycology, $66,74-752$. 
Takeda, K., Takemura, T. \& Kozu, T. (2013). Investment literacy and individual investor biases: Survey evidence in the Japanese stock market, The Review of Socio network Strategies, 7(1), 31-42.

Takeuchi, M. \& Hoshino, T. (2014). Understanding Individual Differences in Financial Behavior by Behavioral Economic Indicators - Influence of Time Discount Rate and Risk Avoidance on Financial and Risk Capital Investment - Summary of the 8th Conference of Behavioral Economics Association (In Japanese).

The Japan Institute for Labour Policy and Training. (2005). Can the Internet survey be used for the social survey? A result by experiment. Reports on Labour Policy, 17 (in Japanese).

Webley, P. \& Nyhus, E. K. (2013). Economic socialization, saving and assets in European young adults, Economics of Education Review, 33, 19-30.

Appendix: Influence of CFC on "Deposit Ratio" and "Stock Ratio": This study analyzes the impact of CFC on the financial assets and liability holdings of individual investors. However, there are various prior studies on the influence of deposit and stock ratios on total financial assets, as shown below. Previous studies have derived several conclusions in this field. For instance, Kinari and Tsutsui (2009) indicate that the time discount rate has no significant influence on the holding ratio of risky assets. They argue that the time discount rate is important in the estimation of the CCAPM Euler equation, but there is no reason for the significant influence on the holding status of financial assets indicated by cross-sectional data at one time point. Kitamura and Nakashima (2010) also show that the time preference rate for stock allocation is not significant. Meanwhile, Nogata and Takemura (2017) demonstrate that the higher the time discount rate, the higher the risky asset holding ratio is they contend.

That individual may desire to earn high earnings in the near future, meaning they are investing in risky and high return risky assets. Feng et al. (2017) show that the time discount rate significantly reduces the risky asset ratio in our study, "deposit ratio" and "equity ratio" (total of stocks and stock investment trusts), which individuals indicate directly from 0 to $100 \%$ in the 2017 survey, are dependent variables, while gender, age, college graduate dummy, investment experience dummy, risk aversion parameter, CFC, CFC-F, and CFC-I are independent variables (Table A1). According to the estimation results, age is not related to the deposit ratio, while individuals with higher age have higher share ratios. In addition, regarding investment experience, the deposit is low and stock ratios are high, among others. However, CFC, CFC-F, and CFC-I do not show statistically significant impacts. Although they all affect the outstanding balance of financial assets, there is no effect on holdings.

Table A1: Estimation Results of the Models for Deposit Ratio and Stock Ratio

\begin{tabular}{|c|c|c|c|c|c|c|c|c|}
\hline & \multicolumn{4}{|c|}{ Ratio of deposit } & \multicolumn{4}{|c|}{ Ratio of stocks } \\
\hline & \multicolumn{2}{|c|}{ model 1} & \multicolumn{2}{|c|}{ model 2} & \multicolumn{2}{|c|}{ model 1} & \multicolumn{2}{|c|}{ model 2} \\
\hline & Coef. & $\mathrm{P}$-value & Coef. & $\mathrm{P}$-value & Coef. & $\mathrm{P}$-value & Coef. & $\mathrm{P}$-value \\
\hline Male dummy & -6.93 & 0.00 & -6.85 & 0.00 & 6.29 & 0.00 & 6.37 & 0.00 \\
\hline Age & 1.06 & 0.15 & 0.96 & 0.19 & 0.04 & 0.96 & -0.07 & 0.91 \\
\hline High education & -2.62 & 0.13 & -2.53 & 0.14 & 0.71 & 0.65 & 0.79 & 0.62 \\
\hline Experience & -12.54 & 0.00 & -12.52 & 0.00 & 7.77 & 0.00 & 7.79 & 0.00 \\
\hline Risk aversion & 0.00 & 0.99 & 0.00 & 0.94 & 0.04 & 0.25 & 0.04 & 0.27 \\
\hline CFC & -1.45 & 0.11 & & & 0.51 & 0.54 & & \\
\hline CFC-F & & & -1.28 & 0.20 & & & -1.24 & 0.18 \\
\hline CFC-I & & & -1.68 & 0.07 & & & 0.33 & 0.70 \\
\hline Constant & 60.27 & 0.00 & 60.60 & 0.00 & 25.22 & 0.00 & 25.55 & 0.00 \\
\hline LR chi2 $(6,7)$ & 81 & & 83 & & 48 & & 50 & \\
\hline Log Likelihood & -56 & 1.8 & -56 & 0.8 & -55 & 1.7 & -550 & 0.9 \\
\hline Pseudo R2 & 0.00 & & 0.00 & 73 & 0.00 & 44 & 0.00 & 46 \\
\hline \# & 12 & & 12 & & 11 & & 11 & 4 \\
\hline
\end{tabular}

